\title{
Indeks Evaluasi Kepuasan Masyarakat pada Pelayanan Perizinan Dinas Penanaman Modal dan Pelayanan Terpadu Satu Pintu Menggunakan Metode algoritma C4.5
}

\author{
Rika Andriani ${ }^{1}$, Poningsih², Muhammad Ridwan Lubis ${ }^{3}$ \\ ${ }^{1}$ STIKOM Tunas Bangsa Pematangsiantar \\ ${ }^{23}$ AMIK Tunas Bangsa Pematangsiantar \\ Jl. Jend. Sudirman Blok A No. 1-3 Pematangsiantar \\ Email : rikaandriani376@gmail.com,
}

\begin{abstract}
At service companies that are customers of the company. Customers can be given lung from a service provider company. Customer satisfaction is formed from the level of achievement and company loyalty. This research supports companies in understanding the level of community satisfaction with services provided by companies in order to improve their performance and loyalty. The method used is the method of data mining with the algorithm c4.5 to obtain results from the decision tree that contains community satisfaction through predetermined criteria. With questionnaires shared with the appraisal community then used as research data.
\end{abstract}

Keywords: Data Mining, C45 Algorithm, Decision Tree, Questionnaire

Abstrak - Pada suatu perusahaan pelayanan jasa terdapat pelanggan yang menjadi konsumen perusahaan tersebut. Pelanggan dapat dikatakan paru-paru dari perusahaan penyedia jasa. Kepuasan pelanggan terbentuk dari tingkat kinerja dan loyalitas perusahaan. Penelitian ini bertujuan untuk membantu perusahaan dalam mengetahui tingkat kepuasan masyarakat terhadap pelayanan yang diberikan perusahaan demi meningkatkan kinerja dan loyalitas mereka. Metode yang digunakan adalah metode data mining dengan algoritma c4.5 untuk mendapatkan hasil berupa pohon keputusan yang menampilkan kepuasan masyarakat melalui kriteria-kriteria penilaian yang telah ditentukan sebelumnya. Dengan kuisioner yang dibagikan kepada masyarakat penilai kemudian digunakan sebagai data penelitian.

Kata Kunci : Data Mining, Algoritma C45, Pohon Keputusan, Kuisioner

\section{PENDAHULUAN}

Pada suatu perusahaan atau instansi tersebut, kepuasan masyarakat menjadi suatu komponen utama demi berjalannya perusahaan ini. Semakin meningkatnya kepuasan masyarakat maka akan semakin meningkat juga kinerja dan pelayanan yang diberikan perusahaan. Dalam penelitian ini akan dijabarkan kepuasan masyarakat terhadap perusahaan mulai dari fasilitas, pelayanan dan tata krama yang diberikan perusahaan untuk masyarakat yang ingin menggunakan jasa perusahaan tersebut.

Dalam beberapa penelitian yang telah dilakukan oleh peneliti yang dituliskan dalam mengambil jurnal menggunakan data mining dengan metode algoritma c4.5 pada perguruan tinggi adalah: beberapa tahun terakhir banyak metode yang digunakan untuk klasifikasi data. "Klasifikasi data mining dengan model algoritma c4.5 dilakukan dengan pengujian-pengujian yang terukur melalui uji AUC, ROC dan 
T-Test dengan bantuan rapid miner. Akurasi pengujian dengan menggunakan algoritma c4.5 masih baik dan dapat dijadikan salah satu pedoman untuk deteksi kredit macet sebelum ada keputusan member atau tidak calon nasabah baru”[1].

\section{METODOLOGI PENELITIAN}

Berikut tahapan dalam penelitian ini yang di rangkum dalam kerangka penelitian :

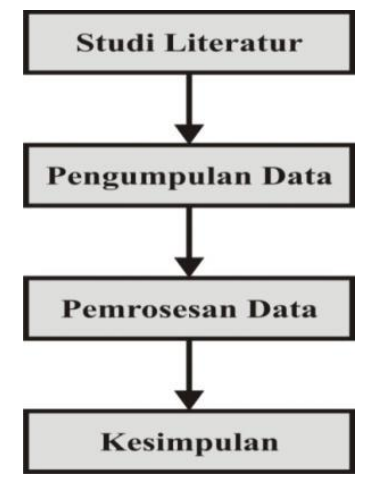

Gambar 1. Kerangka Penelitian

\subsection{Studi Literatur}

Penulis melakukan studi literature tentang masalah yang akan dicari solusinya yang berkaitan dengan algoritma C4.5 dengan memahami kelebihan dan kekurangan algoritma tersebut. Serta algoritma akan menjadi acuan pemecahan masalah dari dasar teori algoritma C4.5.

\subsection{Pengumpulan Data}

Pengumpulan data yang selanjutnya akan disimpulkan yaitu dengan cara pencarian data dengan melakukan kuisioner sehingga mendapatkan data yang dapat digunakan dalam pemecahan masalah. Data yang didapat mencakup data kepuasan pelanggan dimana terdapat bebrapa komponen penilaian didalamnya.

\subsection{Pemrosesan Data}

Data yang didapat akan diidentifikasi serta dievaluasi secara bertahap sehingga mendapatkan data yang relevan dan dapat digunakan sehingga mendapatkan hasil yang sesuai dengan perumusan masalah.

\subsection{Kesimpulan}

Setelah dilakukan beberapa tahapan diatas maka akan tampak hasil yang akan menjadi kesimpulan dari penelitian.

\subsection{Algoritma C4.5}

Algoritma C4.5 merupakan salah satu algoritma Data mining seperti halnya algoritma K-Means [2]-[8]. Algoritma C4.5 adalah algoritma yang sudah banyak dikenal dan digunakan untuk klasifikasi data yang memiliki atribut-atribut numerik dan kategorial. Hasil dari proses klasifikasi yang berupa aturan-aturan dapat digunakan untuk memprediksi nilai atribut bertipe diskret dari record yang baru [9]. Algortima C4.5 sendiri merupakan pengembangan dari algortima ID3, 
dimana pengembangan dilakukan dalam hal, bisa mengatasi missing data, bisa mengatasi data kontinu dan pruning [10].

Rumus mencari nilai entrophy dan gain adalah sebagai berikut:

Entropy $(S)=\sum_{i=0}^{n}-p i * \log _{2}(p i)$

keterangan :

s : Himpunan kasus

n : Jumlah partisi

pi : Jumlah kasus pada partisi ke-i

$\operatorname{GAIN}(S, A)=\operatorname{ENTROPY}(S)-\sum_{I=0}^{N}-\frac{|\operatorname{Si}|}{|S|} * \operatorname{ENTROPY}(S)$

Keterangan :

s : Himpunan kasus

n : Jumlah partisi atribut A

|Si| : Jumlah kasus pada partisi ke-i

|S| : Jumlah kasus dalam s

\section{HASIL DAN PEMBAHASAN}

\subsection{Pengumpulan Data}

Data yang digunakan adalah data yang diperoleh dengan cara melakukan kuisioner yang didapatkan dari masyarakat pengguna jasa pelayanan perusahaan ini.

\subsection{Evaluasi Data}

Data kuisioner yang telah dikumpulkan selanjutnya akan dievaluasi kembali agar lebih mudah untuk diproses dan digunakan sebagai penelitian.

Tabel 1. Data Setelah Dievaluasi

\begin{tabular}{|c|l|l|l|l|l|l|}
\hline No & Keramahan & Penjelasan & Kesabaran & Penampilan & Jangka Waktu & Kepuasan \\
\hline 1 & Ramah & Jelas & Sabar & Rapih & Cepat & Puas \\
\hline 2 & Tidak Ramah & Jelas & Sabar & Tidak Rapih & Cepat & Puas \\
\hline 3 & Sangat Ramah & Tidak Jelas & Tidak Sabar & Rapih & Cepat & Puas \\
\hline 4 & Tidak Ramah & Jelas & Sabar & Rapih & Lama & Puas \\
\hline 5 & Sangat Ramah & Jelas & Sabar & Rapih & Cepat & Puas \\
\hline 6 & Sangat Ramah & Jelas & Tidak Sabar & Rapih & Lama & Puas \\
\hline 7 & Ramah & Jelas & Sabar & Rapih & Cepat & Puas \\
\hline 8 & Sangat Ramah & Tidak Jelas & Sabar & Tidak Rapih & Cepat & Puas \\
\hline 9 & Ramah & Jelas & Sabar & Rapih & Lama & Puas \\
\hline 10 & Sangat Ramah & Jelas & Sabar & Rapih & Cepat & Puas \\
\hline 11 & Ramah & Jelas & Sabar & Rapih & Cepat & Puas \\
\hline 12 & Ramah & Jelas & Sabar & Rapih & Cepat & Puas \\
\hline 13 & Sangat Ramah & Jelas & Sabar & Rapih & Cepat & Puas \\
\hline 14 & Ramah & Jelas & Sabar & Rapih & Cepat & Puas \\
\hline 15 & Sangat Ramah & Jelas & Sabar & Rapih & Cepat & Puas \\
\hline$\ldots$ & $\ldots$ & $\ldots$ & $\ldots$ & $\ldots$ & ... \\
\hline 95 & Ramah & Sangat Jelas & Sabar & Rapih & Lama & Tidak Puas \\
\hline 96 & Ramah & Tidak Jelas & Sabar & Rapih & Lama & Tidak Puas \\
\hline 97 & Sangat Ramah & Jelas & Sabar & Rapih & Lama & Tidak Puas \\
\hline
\end{tabular}




\begin{tabular}{|c|l|l|l|l|l|c|}
\hline No & Keramahan & Penjelasan & Kesabaran & Penampilan & Jangka Waktu & Kepuasan \\
\hline 98 & Ramah & Tidak Jelas & Sabar & Rapih & Cepat & Tidak Puas \\
\hline 99 & Sangat Ramah & Sangat Jelas & Sabar & Rapih & Lama & Tidak Puas \\
\hline 100 & Ramah & Jelas & Sabar & Rapih & Lama & Tidak Puas \\
\hline
\end{tabular}

\subsection{Perhitungan Nilai Entropy dan Nilai Gain}

Data yang telah di evaluasi selanjutnya akan dicari nilai entropy dan nilai gain dengan menggunkan rumus algoritma C4.5. Dapat Dilihat sebagai berikut:

Kriteria : Keramahan, penjelasan, kesabaran, penampilan, jangka waktu

Entrophy [total] $\quad=(-(82 / 100) *(\log 2(82 / 100))+(-18 / 100) *(\log 2(18 / 100))$ $=0.6800770457$

Keramahan

Entrophy [Keramahan-Ramah]

$$
\begin{aligned}
& =(-(46 / 55) *(\log 2(46 / 55))+(-(9 / 55) *(\log 2(9 / 55)) \\
& =0.6429383500
\end{aligned}
$$

Entrophy [Keramahan-Sangat Ramah]

$$
\begin{aligned}
& =(-(34 / 39) *(\log 2(34 / 39))+(-(5 / 39) *(\log 2(5 / 39)) \\
& =0.5524951143
\end{aligned}
$$

Entrophy [Keramahan- Tidak Ramah]

Gain [Keramahan]

$$
=(-(2 / 6) *(\log 2(2 / 6))+(-(4 / 6) *(\log 2(4 / 6))=0.9182958340
$$

Penjelasan

$$
\begin{array}{ll}
=0.6800770455-((55 / 100) * & 0.6429383500)+((39 / 100) * \\
0.5524951143)+((6 / 100) * 0.9182958340)=0.055890108
\end{array}
$$

Entrophy [Penjelasan-Jelas]

$$
\begin{aligned}
& =(-(60 / 66) *(\log 2(60 / 66))+(-(6 / 66) *(\log 2(6 / 66)) \\
& =0.4394969869
\end{aligned}
$$

Entrophy [Penjelasan- Sangat Jelas]

$$
\begin{aligned}
& =(-(20 / 29) *(\log 2(20 / 29))+(-(9 / 29) *(\log 2(9 / 29)) \\
& =0.8935711016
\end{aligned}
$$

Entrophy [Penjelasan- Tidak Jelas]

$$
\begin{aligned}
& =(-(2 / 5) *(\log 2(2 / 5))+(-(3 / 5) *(\log 2(3 / 5)) \\
& =0.9709505944
\end{aligned}
$$

Gain [Penjelasan]

$$
\begin{aligned}
& =0.6800770455-((66 / 100) * 0.4637773495)+((29 / 100) * \\
& 0.8337649065)+((5 / 100) * 0.9709505944) \\
& =0.10683351
\end{aligned}
$$

Kesabaran

Entrophy [Kesabaran-Sabar]

$$
\begin{aligned}
& =(-(80 / 93) *(\log 2(80 / 93))+(-(13 / 93) *(\log 2(13 / 93)) \\
& =0.5836753280
\end{aligned}
$$

Entrophy [Kesabaran-Tidak Sabar]

Gain [Kesabaran]

$$
=(-(2 / 7) *(\log 2(2 / 7))+(-(5 / 7) *(\log 2(5 / 7))=0.8631205685
$$

Penampilan

$$
\begin{aligned}
& =0.6800770455-((93 / 100) * 0.5836753280)+((7 / 100) * \\
& 0.8631205685) \\
& =0.076840551
\end{aligned}
$$


Entrophy [Penampilan-Rapih]

$$
\begin{aligned}
& =(-(80 / 95) *(\log 2(80 / 95))+(-(15 / 95) *(\log 2(15 / 95)) \\
& =0.6292492238
\end{aligned}
$$

Entrophy [Penampilan-Tidak Rapih]

$$
\begin{aligned}
& =(-(2 / 5) *(\log 2(2 / 5))+(-(3 / 5) *(\log 2(3 / 5)) \\
& =0.9709505944
\end{aligned}
$$

Gain [Penampilan]

Jangka Waktu

$$
\begin{aligned}
& =0.6800770455-((95 / 100) * 0.6292492238)+((5 / 100) * \\
& 0.9709505944) \\
& =0.033742753
\end{aligned}
$$

Entrophy [Jangka Waktu-Cepat]

$$
\begin{aligned}
& =(-(78 / 81) *(\log 2(78 / 81))+(-(3 / 81) *(\log 2(3 / 81)) \\
& =0.2285381439
\end{aligned}
$$

Entrophy [Jangka Waktu-Lama]

\begin{tabular}{|c|c|c|c|c|c|c|}
\hline Kriteria & Nilai & Sum & Puas & Tidak & Entrophy & Gain \\
\hline Total & & 100 & 82 & 18 & 0.6800770455 & \\
\hline \multicolumn{6}{|c|}{ Keramahan } & 0.055890108 \\
\hline & Ramah & 55 & 46 & 9 & 0.64293835 & \\
\hline & Sangat Ramag & 39 & 34 & 5 & 0.5524951143 & \\
\hline & Tidak Ramah & 6 & 2 & 4 & 0.918295834 & \\
\hline \multicolumn{5}{|c|}{ Penjelasan } & & 0.10683351 \\
\hline & Jelas & 66 & 60 & 6 & 0.4394969869 & \\
\hline & Sangat Jelas & 29 & 20 & 9 & 0.8935711016 & \\
\hline & Tidak Jelas & 5 & 2 & 3 & 0.9709505944 & \\
\hline \multicolumn{5}{|c|}{ Kesabaran } & & 0.076840551 \\
\hline & Sabar & 93 & 80 & 13 & 0.583675328 & \\
\hline & Tidak Sabar & 7 & 2 & 5 & 0.8631205685 & \\
\hline \multicolumn{6}{|c|}{ Penampilan } & 0.033742753 \\
\hline & Rapih & 95 & 80 & 15 & 0.6292492238 & \\
\hline & Tidak Rapih & 5 & 2 & 3 & 0.9709505944 & \\
\hline \multicolumn{6}{|c|}{ Jangka Waktu } & 0.353888511 \\
\hline & Cepat & 81 & 78 & 3 & 0.2285381439 & \\
\hline & Lama & 19 & 4 & 15 & 0.7424875695 & \\
\hline
\end{tabular}

$$
\begin{aligned}
& =(-(4 / 19) *(\log 2(4 / 19))+(-(15 / 19) *(\log 2(15 / 19)) \\
& =0.7424875695
\end{aligned}
$$

Gain [Jangka Waktu]

$$
\begin{aligned}
& =0.6800770455-((81 / 100) * 0.2285381439)+((19 / 100) * \\
& 0.7424875695) \\
& =0.353888511
\end{aligned}
$$

Setelah dilakukan perhitungan entrophy dan gain seperti diatas, maka selanjutnya hasil yang didapat akan ditampilkan pada tabel node 1 yang akan menjelaskan isi nilai total, nilai entrophy serta nilai gain secara lebih sederhana. Dapat dilihat sebagai berikut :

Tabel 2. Node 1

\subsection{Pembentuka Decision Tree}


Pembentukan pohon keputusan berdasarkan hasil dari nilai entrophy dan gain yang telah dihitung pada tahapan sebelumnya. Dengan demikian perhitungan telah selesai dan akan dilanjutkan pembentukan pohon keputusan dari perhitungan yang telah dilakukan. Pohon keputusan yang dibentuk adalah sebagai berikut :

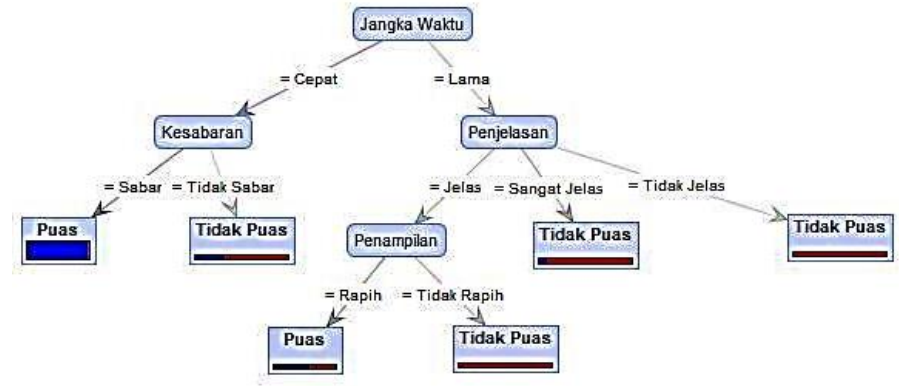

Gambar 2. Pohon Keputusan

\subsection{Hasil Penelitian}

Pohon keputusan yang telah dibentuk akan menampilkan hasil dari penelitian ini yang akan menjadi jawaban dari masalah yang dihadapi. Berdasarkan pohon keputusan diatas maka terdapat rule mode sebagai berikut : Jangka Waktu = Cepat

Kesabaran $=$ Sabar: Puas $\{$ Puas $=77$, Tidak Puas $=1\}$

Kesabaran $=$ Tidak Sabar: Tidak Puas $\{$ Puas=1, Tidak Puas $=2\}$

Jangka Waktu = Lama

Penjelasan $=$ Jelas

Penampilan $=$ Rapih: Puas $\{$ Puas $=3$, Tidak Puas $=2\}$

Penampilan $=$ Tidak Rapih: Tidak Puas $\{$ Puas $=0$, Tidak Puas $=2\}$

Penjelasan $=$ Sangat Jelas: Tidak Puas $\{$ Puas $=1$, Tidak Puas $=9\}$

Penjelasan $=$ Tidak Jelas: Tidak Puas $\{$ Puas $=0$, Tidak Puas $=2\}$

\section{KESIMPULAN} berikut :

Kesimpulan yang dapat diambil dari hasil yang didapat adalah sebagai

a. Jika jangka waktu cepat dan kesabaran menampilkan nilai sabar maka pelanggan akan puas dengan angka. Serta jika jangka waktu cepat tetapi kesabaran menampilkan nilai tidak sabar maka pelanggan tidak puas.

b. Jika jangka waktu lama, penjelasan dengan nilai jelas dan penampilan rapih maka pelanggan puas. Jika waktu lama, penjelasan jelas tetapi penampilan tidak rapih maka pelanggan tidak puas.

c. Jika jangka waktu lama tetapi penjelasan dengan nilai sangat jelas maka pelanggan puas. Serta jika jangka waktu lama dan penjelasan tidak jelas maka pelanggan tidak puas.

\section{DAFTAR PUSTAKA}

[1] M. A. Usman, E. Santoso, and N. Hidayat, "Sistem Pendukung Keputusan Pemilihan Anggota Pengurus Harian Pondok Pesantren Menggunakan Metode Profile Matching ( Studi Kasus Pondok Pesantren Putra Sabilurrosyad )," vol. 1, no. 10, pp. 1176-1184, 2017.

[2] I. Parlina, A. P. Windarto, A. Wanto, and M. R. Lubis, "Memanfaatkan Algoritma K-Means dalam Menentukan Pegawai yang Layak Mengikuti Asessment Center untuk Clustering 
Program SDP," CESS (Journal of Computer Engineering System and Science), vol. 3, no. 1, pp. 87-93, 2018.

[3] R. W. Sari, A. Wanto, and A. P. Windarto, "Implementasi Rapidminer dengan Metode KMeans (Study Kasus: Imunisasi Campak pada Balita Berdasarkan Provinsi)," KOMIK (Konferensi Nasional Teknologi Informasi dan Komputer), vol. 2, no. 1, pp. 224-230, 2018.

[4] M. G. Sadewo, A. P. Windarto, and A. Wanto, "Penerapan Algoritma Clustering dalam Mengelompokkan Banyaknya Desa/Kelurahan Menurut Upaya Antisipasi/ Mitigasi Bencana Alam Menurut Provinsi dengan K-Means," KOMIK (Konferensi Nasional Teknologi Informasi dan Komputer), vol. 2, no. 1, pp. 311-319, 2018.

[5] M. G. Sadewo, A. P. Windarto, and D. Hartama, "Penerapan Datamining Pada Populasi Daging Ayam Ras Pedaging Di Indonesia Berdasarkan Provinsi Menggunakan K-Means," InfoTekJar (Jurnal Nasional Informatika dan Teknologi Jaringan), vol. 2, no. 1, pp. 60-67, 2017.

[6] S. Sudirman, A. P. Windarto, and A. Wanto, "Data Mining Tools | RapidMiner: K-Means Method on Clustering of Rice Crops by Province as Efforts to Stabilize Food Crops In Indonesia," IOP Conference Series: Materials Science and Engineering, vol. 420, no. 12089, pp. 1-8, 2018.

[7] A. P. Windarto, "Penerapan Data Mining Pada Ekspor Buah-Buahan Menurut Negara Tujuan Menggunakan K-Means Clustering," Techno.COM, vol. 16, no. 4, pp. 348-357, 2017.

[8] A. P. Windarto, "Implementation of Data Mining on Rice Imports by Major Country of Origin Using Algorithm Using K-Means Clustering Method," International Journal of artificial intelligence research, vol. 1, no. 2, pp. 26-33, 2017.

[9] H. Siahaan, H. Mawengkang, S. Efendi, A. Wanto, and A. P. Windarto, "Application of Classification Method C4 . 5 on Selection of Exemplary Teachers," in IOP Conference Series, 2018, pp. 1-6.

[10] E. Elisa, "Analisa dan Penerapan Algoritma C4.5 Dalam Data Mining Untuk Mengidentifikasi Faktor-Faktor Penyebab Kecelakaan Kerja Kontruksi PT.Arupadhatu Adisesanti," Jurnal Online Informatika, vol. 2, no. 1, p. 36, 2017. 